\title{
Direct Costs of Diabetes Care in Pediatric Patients with Type 1 Diabetes in Greece
}

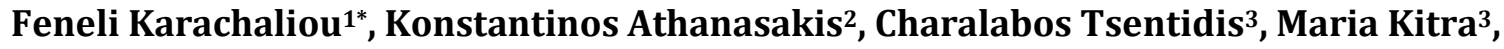 \\ John Kyriopoulos ${ }^{2}$, Kyriaki Karavanaki ${ }^{3}$ \\ ${ }^{1}$ Department of Endocrinology-Growth and Development, “P. \& A. Kyriakou” Children's Hospital, Athens, \\ Greece \\ ${ }^{2}$ Department of Health Economics National School of Public Health, Athens, Greece \\ ${ }^{3}$ Diabetic Clinic, 2nd University Department of Pediatrics, “P. \& A. Kyriakou” Children's Hospital, Athens, \\ Greece \\ Email: ${ }^{*}$ fenkar1@hotmail.com
}

Received 7 June 2014; revised 2 July 2014; accepted 30 July 2014

Copyright (C) 2014 by authors and Scientific Research Publishing Inc.

This work is licensed under the Creative Commons Attribution International License (CC BY). http://creativecommons.org/licenses/by/4.0/

(c) (i) Open Access

\section{Abstract}

Background: Type 1 diabetes (T1D) is a chronic disease with increasing incidence and major impact on the health care costs. Aim: To estimate the direct cost of pediatric T1D in the Greek National Health System (NHS) and its distribution by service category. Methods: This is a retrospective cost-of-illness study, focusing on the direct costs from the healthcare system's point of view. All patients aged 0 - 16 years, diagnosed with T1D, who were followed in the Diabetes Outpatients' Clinic of the University Pediatric Department of one of the two main Pediatric Hospitals in Athens, for a two-year period (1 $1^{\text {st }}$ January 2011 to $31^{\text {st }}$ December 2012) were included. Results: Total diabetes-related direct costs per person-year were estimated at $€ 2,712$ (95\% CI 2468 - 2956). Diabetes healthcare provider and education visits including laboratory tests, accounted for only $7.6 \%$ of total costs. Cost for hospitalizations was only $1.7 \%$. Medication costs were $17 \%$ of total costs and were the highest for multi-injection therapy. Supply costs accounted for $73.7 \%$ of the total costs and were the highest for insulin pump therapy $(p=0.000) .12 .4 \%$ of patients were admitted yearly for diabetes related cause and the mean length of hospitalization was 0.18 days per person-year (95\%CI: $0.05-0.3)$. Conclusion: This is a preliminary study based on a single institution's data, which however constitutes a major referral center, thus dealing with a balanced sample of the Greek pediatric diabetic population. Considering that standards of diabetes care are common throughout the NHS, the management of patients in our hospital represents the common practice for pediatric diabetes in Greece. Data are suggesting that cost for hospitalization and outpatients' care for T1D patients followed in the public sector was rather low compared to other countries, the medication cost was at similar or lower levels and the cost of supplies was generally higher.

\footnotetext{
${ }^{*}$ Corresponding author.

How to cite this paper: Karachaliou, F., Athanasakis, K., Tsentidis, C., Kitra, M., Kyriopoulos, J. and Karavanaki, K. (2014) Direct Costs of Diabetes Care in Pediatric Patients with Type 1 Diabetes in Greece. Journal of Diabetes Mellitus, 4, $209-215$. http://dx.doi.org/10.4236/jdm.2014.43030
} 


\section{Keywords}

\section{Type 1 Diabetes Mellitus, Economics, Cost}

\section{Introduction}

Type 1 diabetes (T1D) is a chronic disease with increasing incidence and severe long-term complications. Its impact on the rising health care costs is often overlooked, since most of the studies focus on type 2 diabetes (T2D), which is a more common type of the disease. In several cost studies, the two types of the disease are combined. However, although T1D patients represent only 5\% - 10\% of the diabetic population, the cost attributed to T1D is disproportionately high [1].

There is a paucity of published data on the economics of T1D in the literature. In Germany, Icks et al. [2] estimated that mean total direct cost per patient-year was $€ 2611$ in 2004. This number was increased to $€ 3524$ in a recent study evaluating the cost of T1D in the same country in 2007, an average increase of $20 \%$ per patient while the total annual cost of pediatric diabetes was increased by $47 \%$ [3]. The annual cost for T1D in a recent study from Texas, USA, in 2011 was estimated at \$4730 [4] and was shown to be inversely correlated to the degree of metabolic control. Further, the Diabetes Control and Complication Trial estimated that the annual cost of T1D is strongly associated with the regimen of therapy, being threefold higher in intensive therapy (\$4000 in multi injection and \$5800 in pump therapy) compared to conventional therapy (\$1700 for injections twice a day) [5].

To the best of our knowledge, apart from the studies from Germany [2] [3], France [6], UK [7] [8] and Texas [4], there are no data from southern European countries, and especially those affected by the economic crisis, such as Greece, relating to the cost of T1D in the pediatric population and its distribution by category of health service.

To examine the true economic impact of the disease, both medical and non medical costs need to be estimated. The aim of this study was to estimate the direct cost of pediatric T1D in the Greek National Health System and its distribution by service category.

\section{Patients and Methods}

Our cohort included all patients with T1D, who were followed in the University Department of "P. \& A. Kyriakou" Children's Hospital, one of the two main pediatric hospitals in Athens, from $1^{\text {st }}$ January 2011 to $31^{\text {st }}$ December 2012. It is a retrospective cost-of-illness study focusing on the direct costs from the healthcare system point of view.

The first 6-months' interval after diagnosis of T1D is a high cost period since it entails the initial hospitalization (usually 7 - 10 days) and frequent outpatient appointments for glycaemic stabilization and educational purposes. Since this study focused on the long-term maintenance of diabetes costs, the cost of the first 6 months following diagnosis was excluded from the analysis. Consequently, patients with a duration of diabetes of less than 6 months were excluded from the study. The final analysis involved 89 patients.

Data concerning gender, ethnicity and duration of diabetes were collected. Also the average total daily dose of insulin was estimated. Insulin regimen was also recorded as conventional (two injections a day), intensive multi-injection ( $\geq 4$ injections a day) and intensive pump therapy. Metabolic control was estimated as the mean of all HbA1c measurements obtained for each patient over the 2-year study period.

All laboratory examinations for each patient during the study period were recorded and their cost was estimated based on the National Health System prices. These tests included a yearly check-up of biochemistry, of associated autoimmunity and estimation of microalbumin levels in a $24 \mathrm{~h}$ urine collection.

All visits at the diabetic outpatient clinic over the study period were recorded. Since a diabetic clinic was carried out twice a week, the cost of each visit was estimated as the $20 \%$ of the monthly physician's salary divided by the average number of patients seen in a month plus the cost of the specialist nurse estimated in the same way. Visits to dietitians, ophalmologists, nehprologists or any other subspecialities necessary for the assessment of diabetes-related conditions were estimated at the base of the cost of an outpatient visit in the Hospital.

All diabetes-related admissions during the 2-year period were counted, the number of hospital days was recorded and the cost was estimated based on the National System Diagnosis Related Groups (DRGs).

The cost of medication was estimated from the total daily insulin dose based on the commercial prices of the used types of insulin. Additionally the cost of glucagon used for the control of hypoglycaemic episodes was added to the calculations. 
Finally, the cost of supplies was estimated based on the monthly cost of strips, lancets, syringes to which each patient is entitled. For the patients who were diagnosed during the study period the price of the glucose measuring device was added. For the patients using a pump the monthly cost of pump supplies (infusion sets etc.) was estimated and the cost of the pump hardware was also calculated for those who started the pump during the 2-year study period.

All costs were estimated for each patient for the months studied during the 2-yr study period and then annualized.

\section{Statistical Methods}

Data were expressed as mean \pm sd. Non-parametric tests (Mann-Whitney test and Kruskall-Wallis test respectively) were used for data not normally distributed. Costs were expressed as total costs per patient-year and stratified for the different test categories. Mean costs and 95\% CIs were determined for all cost categories. Analysis was performed using SPSS, version 17.0.

\section{Results}

The demographic and clinical characteristics of the children of our cohort are shown in Table 1 . The study included 45 boys and 44 girls with a mean \pm SD age of $12.05 \pm 5.15$ years, of whom $76 \%$ were Greeks. The mean \pm SD duration of disease was $4.9 \pm 3.88$ years and then mean time of data record was 21.3 months. The mean $\mathrm{HbA} 1 \mathrm{c}$ of the patients was $8.2 \pm 1.5 \%$ (66nmol/mol). The mean daily insulin dose was $0.85 \mathrm{U} / \mathrm{kg}$. The majority of patients (80\%) were on intensive multi-injection regimen, $10 \%$ on conventional regimen and $10 \%$ on an insulin pump. The comparison of the population characteristics and costs according to therapeutic regimen are shown in Table 2. The mean age of the patients was significantly different among the three groups $(\mathrm{p}=0.001)$ with the group on conventional regimen being the youngest one (5.36 vs 12.71 years, $p=0.001$ ) with the shortest diabetes duration (2.66 vs 5.05 years, $\mathrm{p}=0.040)$. The mean daily insulin dose was significantly different among the three groups $(\mathrm{p}=0.001)$, with the pump group having the lowest mean daily insulin dose $(\mathrm{p}=0.001)$. The HbA1c levels were marginally significantly different among the three regimen groups $(p=0.059)$, with the pump group having the best control (HbA1c: 7.23\%) and the conventional treatment group having the poorest control (HbA1c: 8.5\%, p = 0.020).

\subsection{Cost of Admissions}

11 patients (12.4\%) were hospitalized for at least one time during the 2-yr period. The duration of hospitalization varied between one and five days, with a mean length of hospitalization 0.18 days per person-year (95\% CI: $0.05-0.3$ ). The causes were all diabetes related (severe hypoglycaemia, diabetic ketoacidosis, metabolic dysregulation during febrile illness). Mean number of hospitalization per person-year was 0.067 (95\% CI: 0.03 - 0.1 ). None of the patients of our cohort during the study period needed an emergency room admission.

The mean cost for hospitalizations per person-year was $€ 47$ (95\% CI: 12 - 82), with no significant difference among the three regimen groups.

Table 1. Clinical and demographic characteristics $(n=89)$.

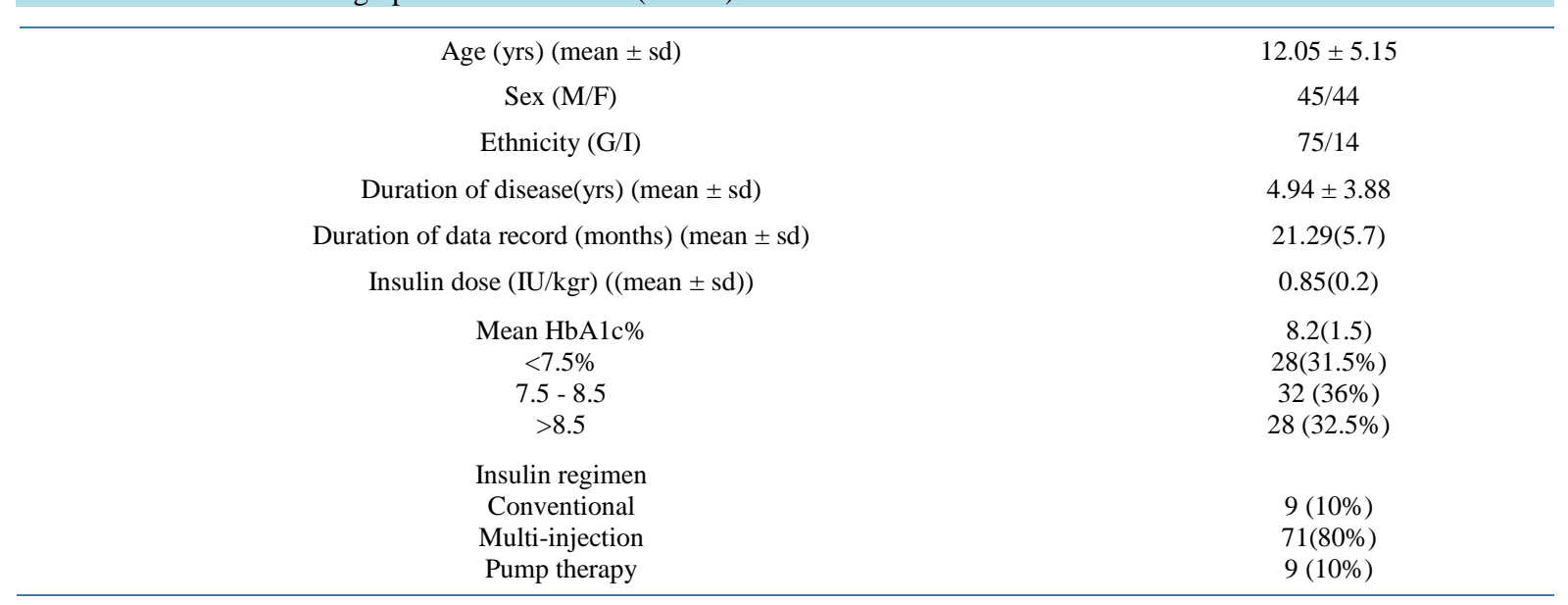


Table 2. Comparison of population characteristics and costs according to therapeutic regimen.

\begin{tabular}{|c|c|c|c|c|}
\hline $\begin{array}{l}\text { Population } \\
\text { characteristics }\end{array}$ & $\begin{array}{l}\text { Conventional } \\
\text { mean, } 95 \% \text { CI } \\
\mathrm{N}=9 \text { (a) }\end{array}$ & $\begin{array}{l}\text { Multi-injection } \\
\text { mean, 95\% CI } \\
\mathrm{N}=71 \text { (b) }\end{array}$ & $\begin{array}{l}\text { Pump } \\
\text { mean, 95\% CI } \\
\mathrm{N}=9 \text { (c) }\end{array}$ & $\begin{array}{l}\mathrm{p} \\
\text { Kruskall-Wallis }\end{array}$ \\
\hline Age (yrs) & $\begin{array}{l}5.36 \pm 2.99 \\
\text { (a) vs (b) } p=0.001\end{array}$ & $\begin{array}{l}12.71 \pm 5.04 \\
\text { (b) vs (c) } p=0.641\end{array}$ & $\begin{array}{l}13.51 \pm 2.15 \\
\text { (a) vs (c) } p=0.001\end{array}$ & 0.001 \\
\hline Diabetes duration (yrs) & $\begin{array}{l}2.66 \pm 1.85 \\
\text { (a) vs (b) } p=0.067\end{array}$ & $\begin{array}{l}5.05 \pm 3.78 \\
\text { (b) vs (c) p }=0.233\end{array}$ & $\begin{array}{l}6.72 \pm 5.14 \\
\text { (a) vs (c) } p=0.040\end{array}$ & 0.074 \\
\hline HbA1c (\%) & $\begin{array}{l}8.5 \pm 0.98 \\
\text { (a) vs (b) } p=0.553\end{array}$ & $\begin{array}{l}8.21 \pm 1.32 \\
\text { (b) vs (c) } p=0.036\end{array}$ & $\begin{array}{l}7.23 \pm 1.01 \\
\text { (a) vs (c) } p=0.020\end{array}$ & 0.059 \\
\hline $\begin{array}{l}\text { Total dose } \\
\text { (Iu/kg/day) }\end{array}$ & $\begin{array}{l}0.90 \pm 0.22 \\
\text { (a) vs (b) } p=0.353\end{array}$ & $\begin{array}{l}0.90 \pm 0.22 \\
\text { (b) vs (c) } p=0.017\end{array}$ & $\begin{array}{l}0.72 \pm 0.07 \\
\text { (a) vs (c) } p=0.001\end{array}$ & 0.001 \\
\hline \multicolumn{5}{|l|}{$\begin{array}{l}\text { Cost by service } \\
\text { category (euro/pppy) }\end{array}$} \\
\hline Outpatient visits & $\begin{array}{l}66(21-111) \\
\text { (a) vs (b) } p=0.807\end{array}$ & $\begin{array}{l}65(55.5-74) \\
\text { (b) vs (c) p = } 0.320\end{array}$ & $\begin{array}{l}74(42-106) \\
\text { (a) vs (c) } p=0.492\end{array}$ & 0.69 \\
\hline Laboratory tests & $\begin{array}{l}151(45-257) \\
\text { (a) vs (b) } p=0.691\end{array}$ & $\begin{array}{l}137(116-158) \\
\text { (b) vs (c) } p=0.564\end{array}$ & $\begin{array}{l}156.5(57-256) \\
\text { (a) vs (c) } p=0.928\end{array}$ & 0.97 \\
\hline Hospitalizations & $\begin{array}{l}67(38-173) \\
\text { (a) vs (b) } p=0.793\end{array}$ & $\begin{array}{l}45(3-87) \\
\text { (b) vs (c) } p=0.371\end{array}$ & $\begin{array}{l}41(53-134) \\
\text { (a) vs (c) } p=0.332\end{array}$ & 0.65 \\
\hline Medications & $\begin{array}{l}125(71-179) \\
\text { (a) vs (b) } \mathrm{p}=0.001\end{array}$ & $\begin{array}{l}500(441-560) \\
\text { (b) vs (c) p = 0.635 }\end{array}$ & $\begin{array}{l}450(337-581) \\
\text { (a) vs (c) } \mathrm{p}=0.001\end{array}$ & 0.000 \\
\hline Supplies & $\begin{array}{l}1570(1341-1798) \\
\text { (a) vs (b) p = } 0.360\end{array}$ & $\begin{array}{l}1699.5(1603-1796) \\
\text { (b) vs (c) } p=0.001\end{array}$ & $\begin{array}{l}4808 \text { (3707 - 5909) } \\
\text { (a) vs (c) } p=0.001\end{array}$ & 0.000 \\
\hline Total cost & $\begin{array}{l}1978.5(1682-2275) \\
\text { (a) vs (b) } p=0.014\end{array}$ & $\begin{array}{l}2447(2320-2574) \\
\text { (b) vs (c) p }=0.001\end{array}$ & $\begin{array}{l}5538(4480-6597) \\
\text { (a) vs (c) p = } 0.001\end{array}$ & 0.000 \\
\hline
\end{tabular}

\subsection{Cost of Laboratory Tests}

The mean cost for laboratory tests per person-year was €141 (95\% CI 120 - 161), with no significant difference among the three regimen groups.

\subsection{Cost of Outpatient Visits}

All patients had at least one outpatient visit in diabetic clinic during the 2-yr period. The mean number of outpatient visits per year was 2.88 (95\% CI: 2.5 - 3.2). The mean cost of outpatient visits in diabetic clinic per person-year was $€ 65$ (95\% CI: 55 - 78), with no significant difference among the three regimen groups. During the study period 30 patients (33.7\%) needed once an ophthalmologist evaluation. The total mean cost of outpatients visits per person-year was €66 (95\% CI: 57 - 75).

\subsection{Cost of Medications}

Nine only (10\%) of the patients were on conventional (2 injections/day) regimen, nine (10\%) on pump and 71 (80\%) were on multi-injection scheme. The mean cost for medication per person-year was $€ 458$ (95\% CI 390 497). The cost of medications differed significantly $(p=0.000)$ among the three groups, being much lower for the patients on conventional regimen, compared with patients on pump ( $€ 125$ vs $€ 450, p=0.001)$ and those on multi-injection regimen (€500, $\mathrm{p}=0.001)$ (Table 2).

\subsection{Cost of Supplies}

During the 2-year period, there were 18 newly diagnosed children who needed a glucose-measuring device (mean cost €35 per device). Six children started using the pump and needed the device (mean cost of €2770). Another 4 children in this study group were already on pump, thus the monthly cost of pump supplies was calculated for these 10 children (average $€ 350 /$ month). The mean total cost for the rest of supplies (needles, strips, lancets) was estimated at $€ 145.85 /$ month, according to the monthly allowed cost for each patient from the Greek National Health System.

The total mean cost of supplies per person-year was €2000.71 (SD: 1107, 95\% CI 1767.5 - 2234). The cost 
differed significantly among the three regimen groups (Kruskall Wallis test $=27.05, \mathrm{p}=0.000$ ), being the highest for the patients on pump therapy (€4808). This cost was significantly higher than that of patients on multi-injection ( $€ 1699.5, \mathrm{p}=0.001)$ and those on conventional scheme $(€ 1570, \mathrm{p}=0.001)$ (Table 2$)$.

\subsection{Total Costs}

Total diabetes-related direct costs per person-year were estimated at €2712 (95\% CI 2468-2956, Table 3). Diabetes healthcare provider and education visits accounted for only $2.4 \%$ of total costs. Even when the cost of laboratory tests performed during these visits was combined, ambulatory care accounted for $7.6 \%$ of total costs. Cost for hospitalizations was only $1.7 \%$. Medication costs were $17 \%$ of total costs and were the highest for multi-injection therapy. Supply costs accounted for $73.7 \%$ of the total costs and were the highest for insulin pump therapy (Table 3). Consequently patients on pump therapy had significantly higher cost $€ 5538$ compared to patients on multi-injection $€ 2447(\mathrm{p}=0.001)$ and conventional regimen $€ 1978.5(\mathrm{p}=0.001)$ (Table 2).

\section{Discussion}

This is a preliminary study examining direct costs of illness in pediatric patients with type 1 diabetes in Greece from the healthcare system point of view.

The mean annual cost was found to be $€ 2712$ per person for the study period (2011-2012).

The amount of $€ 2712$ was close to the cost reported in studies from USA (\$4730, 95CI: 4516 - 4944) (i.e. $€ 3730)$ in 2011 [4]. It is also close to the cost reported in Great Britain, estimated at 1399 pounds (€2059) for primary care treatment and at 3233pounds (€4744) for total cost, by a simple combination of inpatient [7] and outpatient [8] costs by type [9]. Similarly, in 2007, The Economist estimated total per patient costs to be $\$ 4,794$ in UK, as part of an international study [10] (Table 4).

In France, French ENTRED 2007 data estimate the total cost for T1D at $€ 6927$ per patient. Annual outpatient costs per patient with T1D were estimated at $€ 4329$ and annual inpatient costs per patient at $€ 2597$ [6].

Finally in Germany, mean direct diabetes-associated costs per patient were 3524 euro, with the total costs of pediatric diabetes care exceeding $€ 110$ million in 2007 [3].

In Italy, cost data are provided from 2 studies published in 2010 [11] and 2011 [12] and referring to 2008 and 2010 respectively. According to them, total direct diabetes-associated costs are reported to reach $€ 7.94$ billion in 2010, with T1D being twice as costly as T2D patients [11].

The most recent study of Spanish national diabetes direct costs calculates per patient costs at $€ 1708$ annually for Type 1 \& 2; 2002 costs were extrapolated to 2010 [13]. Data did not differentiate between type 1 and 2 .

Table 3. Cost by service category.

\begin{tabular}{ccc}
\hline Service category & Mean (euro/pppy) (95\% CI) & \% annual cost \\
\hline Outpatient visits & $69(27-35.0)$ & $2.4 \%$ \\
Hospitalizations & $47(9-80)$ & $5.2 \%$ \\
Laboratory tests & $141(120-161)$ & $73.7 \%$ \\
Supplies & $2001(2092-2592)$ & $17 \%$ \\
Medications & $458(390-497)$ & $100 \%$ \\
Total cost & $2712(2740-3262.5)$ & \\
\hline
\end{tabular}

Table 4. Annual cost per person with diabetes type 1 in different countries.

\begin{tabular}{|c|c|c|c|c|c|}
\hline & Outpatient visits & Hospitalization & Supplies & Medication & Total annual cost (pppy) \\
\hline Greece 2012 & $2.4 \%+5.2=7.6 \%$ & $1.7 \%$ & $73.7 \%$ & $17 \%$ & $€ 2712$ (outpatient) \\
\hline USA 2005 (4) & $10 \%$ & $19 \%$ & $38 \%$ & $33 \%$ & $\$ 4730$ (outpatient) \\
\hline Germany 2004 (2) & & $26 \%$ & $44 \%$ & $21 \%$ & $€ 2611$ (out- and inpatient) \\
\hline Germany 2007 (3) & & $32 \%$ & $47 \%$ & $15 \%$ & $€ 3524$ out-and inpatient) \\
\hline France (6) & & & & & $\begin{array}{l}€ 4329 \text { outpatient } \\
€ 2597 \text { inpatient }\end{array}$ \\
\hline $\mathrm{UK}(7,8)$ & & & $31.3 \%$ & $17.7 \%$ & $\begin{array}{c}€ 2059 \text { (1399 pounds) outpatient } \\
€ 4744 \text { (3.233 pounds) } \\
\text { Out- and inpatient) }\end{array}$ \\
\hline
\end{tabular}


In our study, the majority of costs $73.7 \%$ concerned supplies and it was significantly higher for patients using the pump (€5538 per person-year) compared with patients on multi-injection regimen (€2477 per person-year) and patients on conventional scheme (€1978 per person-year). The association of supply costs with the regimen is reasonable and is also reported in all countries [2] [4].

The distribution of costs by category of service could not be compared to other European countries due to structural differences in healthcare systems and data collection methodologies. When comparing our data to those from the USA study in which the direct cost of T1D care was estimated in a similar way, it was observed that the costs by category of service were distributed in a different way. The cost of supplies in our study represented $73.7 \%$ of the total cost compared to $38 \%$ in USA. It is possible that this cost is overestimated to a certain degree as it was based on the cost of the supply allowances for each patient and not the actually used ones. Thus, if patients measured their blood sugar less frequently and thus used less supplies than the amount that they were entitled to, this could not be captured. The medication cost represented $17 \%$ of total cost, compared to 33\% in USA [4]. The relatively lower medication cost could be attributed to the lower prices of the insulins. This cost was estimated on the daily insulin dose for each patient, thus representing the true cost and matched well with the cost of medication in other European countries [7]. The cost of outpatients' visits at 7.6\% (including the necessary laboratory tests performed during the visits) was rather low, due to relatively low number of outpatient visits per person per year pppy (2.88 visits pppy) and relatively low healthcare provider compensations. Finally the hospitalization cost for diabetes related causes in our study was very low $(1.7 \%$ of the total cost) due to both low admission rate and low cost of day of hospitalization. The admission rate for diabetes-related causes in our study was 0.067 admission pppy and was lower to that reported in Germany (0.45 ppyy) [14] and USA (0.1 ppyy) [4]. Also the mean number of hospital days was low 0.18 days ppyy compared to that reported in other studies in Europe [9] and USA [4], although data are not entirely comparable. The low admission rate for diabetes related causes, resulting in low hospitalization cost can be attributed to the continuous 24 $\mathrm{h}$ support of the families by the diabetic team for the management of different problems of glycaemic control.

To the best of our knowledge this is the first study examining direct costs of T1D in Greece. However, there are several limitations. First, as this study aimed to focus on the long-term maintenance cost of T1D, the analysis did not include costs of the first post diagnosis 6-months period, which contribute disproportionally high to the total cost. Also this analysis included pediatric patients of a mean age of 12.05 years with a mean duration of disease of 4.94 years, in whom impaired indices of early microvascular complications can be observed, but development clinical symptoms and signs of complications (which constitute a major component of the cost in adult patients) is extremely rare and was not observed in any of the patients of our cohort.

Also, the analysis was restricted only to direct costs and these were evaluated for patients followed-up on an outpatient basis in the public sector. Previous studies suggest that inpatient costs account for around $50 \%$ of total healthcare costs for people with diabetes [2]. Although the study is based on a single institution's data, it is important to emphasize that this is a major referral center from central and southern Greece and the Aegean islands, thus dealing with a balanced sample of the Greek pediatric diabetic population. Similarly, as the standards of diabetes care are common throughout the NHS, the management of T1D patients in our hospital represents the common practice for the disease in Greece.

\section{Conclusion}

To conclude, very few studies have assessed the total cost of T1D, especially in countries affected by the economic crisis and there is a need for up-to-date estimates. This is a preliminary study, reporting that the annual cost of diabetes care in Greece is lower than in other countries, with the cost of supplies representing the majority of annual direct costs and the pump therapy being the most expensive therapeutic regimen, while the hospitalization cost was very low. It is necessary that the study is expanded to greater numbers of pediatric patients with T1D in order to assess the relationship of the diabetes care cost with different demographic and clinical parameters and target the effort towards achieving the best clinical outcomes with the less possible cost.

\section{References}

[1] Tao, B.T. and Taylor, D.G. (2010) Economics of Type 1 Diabetes. Endocrinology Metabolism Clinics of North America, 39, 499-512. http://dx.doi.org/10.1016/j.ecl.2010.05.004

[2] Icks, A., Rosenbauer, J., Rathmann, W., Haastert, B., Gandjour, A. and Giani, G. (2004) Direct Costs of Care in Ger- 
many for Children and Adolescents with Diabetes Mellitus in the Early Course after Onset. Journal of Pediatric Endocrinology and Metabolism, 17, 1551-1559. http://dx.doi.org/10.1515/JPEM.2004.17.11.1551

[3] Bächle, C.C., Holl, R.W., Straßburger, K., Molz, E., Chernyak, N., Beyer, P., Schimmel, U., Rütschl, H., Seidel, J., Lepler, R., Holder, M., Rosenbauer, J., Icks, A., DPV Initiative German BMBF Competence Network Diabetes Mellitus (2012) Costs of Paediatric Diabetes Care in Germany: Current Situation and Comparison with the Year 2000. Diabetic Medicine, 29, 1327-1334. http://dx.doi.org/10.1111/j.1464-5491.2012.03645.x

[4] Ying, A.K., Lairson, D.R., Giardino, A.P., Bondy, M.L., Zaheer, I., Haymond, M.W. and Heptulla, R.A. (2011) Predictors of Direct Costs of Diabetes Care in Pediatric Patients with Type 1 Diabetes. Pediatric Diabetes, 12, 177-182. http://dx.doi.org/10.1111/j.1399-5448.2010.00680.x

[5] DCCT Research Group (1995) Resource Utilization and Costs of Care in the Diabetes Control and Complications Trial. Diabetes Care, 18, 1468-1478. http://dx.doi.org/10.2337/diacare.18.11.1468

[6] Ricci, P., Chantry, M., Levy, B., Poutignat, N., Kusnik-Joinville, O., Raimond, V., Thammavong, N. and Weill, A. (2009) Coûts des Soins Remboursés par L‘Assurance Maladie aux Personnes Traitées pour Diabète: Études Entred 2001 et 2007. Bulletin Épidemiologique Hebdomadaire, 42-43,464-469.

[7] Morgan, C., Peters, J.R., Dixon, S. and Currie, C.J. (2010) Estimates Costs of Acute Hospital Care for People with Diabetes in the United Kingdom: A Routine Record Linkage Study in a Large Region. Diabetic Medicine, 27, 1066-1073. http://dx.doi.org/10.1111/j.1464-5491.2010.03086.x

[8] Currie, C.J., Gale, E.A. and Poole, C.D. (2010) Estimation of Primary Care Treatment Costs and Treatment Efficacy for People with Type 1 and Type 2 Diabetes in the United Kingdom from 1997 to 2007. Diabetic Medicine, 27, 938948. http://dx.doi.org/10.1111/j.1464-5491.2010.03040.x

[9] Kanavos, P., van der Aardweg, S. and Schurer W. LSE Health, London School of Economics (2012) Diabetes Expenditure, Burden of Disease and Management in 5 EU Countries. http://www.lse.ac.uk/lsehealthandsocialcare

[10] The Economist Intellegence Unit (2007) The Silent Epidemic: An Economic Study of Diabetes in Developed and Developing Countries. The Economist.

[11] Marchesini, G., Forlani, G., Rossi, E., Berti, A., De Rosa, M. and on Behalf of the ARNO Working Group (2011) The Direct Economic Cost of Pharmacologically-Treated Diabetes in Italy-2006. Nutrition, Metabolism \& Cardiovascular Diseases, 21, 339-346. http://dx.doi.org/10.1016/j.numecd.2009.10.009

[12] Osservatorio Arno Diabete (2011) ll Profilo Assistenziale Della Popolazione con Diabete. CINECA, Collana Rapporti Arno.

[13] Oliva, J., Lobo, F., Molina, B. and Monereo, S. (2004). Direct Health Care Costs of Diabetic Patients in Spain. Diabetes Care, 27, 2616-2621. http://dx.doi.org/10.2337/diacare.27.11.2616

[14] Bächle, C., Haaster, B., Holl, R.W., Beyer, P., Grabert, M., Giani, G. and Icks, A. (2010) Inpatient and Outpatient Health Care Utilization of Children and Adolescents with Type 1 Diabetes before and after Introduction of DRGs. Experimental and Clinical Endocrinology Diabetes, 118, 644-648. http://dx.doi.org/10.1055/s-0030-1249673 
Scientific Research Publishing (SCIRP) is one of the largest Open Access journal publishers. It is currently publishing more than 200 open access, online, peer-reviewed journals covering a wide range of academic disciplines. SCIRP serves the worldwide academic communities and contributes to the progress and application of science with its publication.

Other selected journals from SCIRP are listed as below. Submit your manuscript to us via either submit@scirp.org or Online Submission Portal.
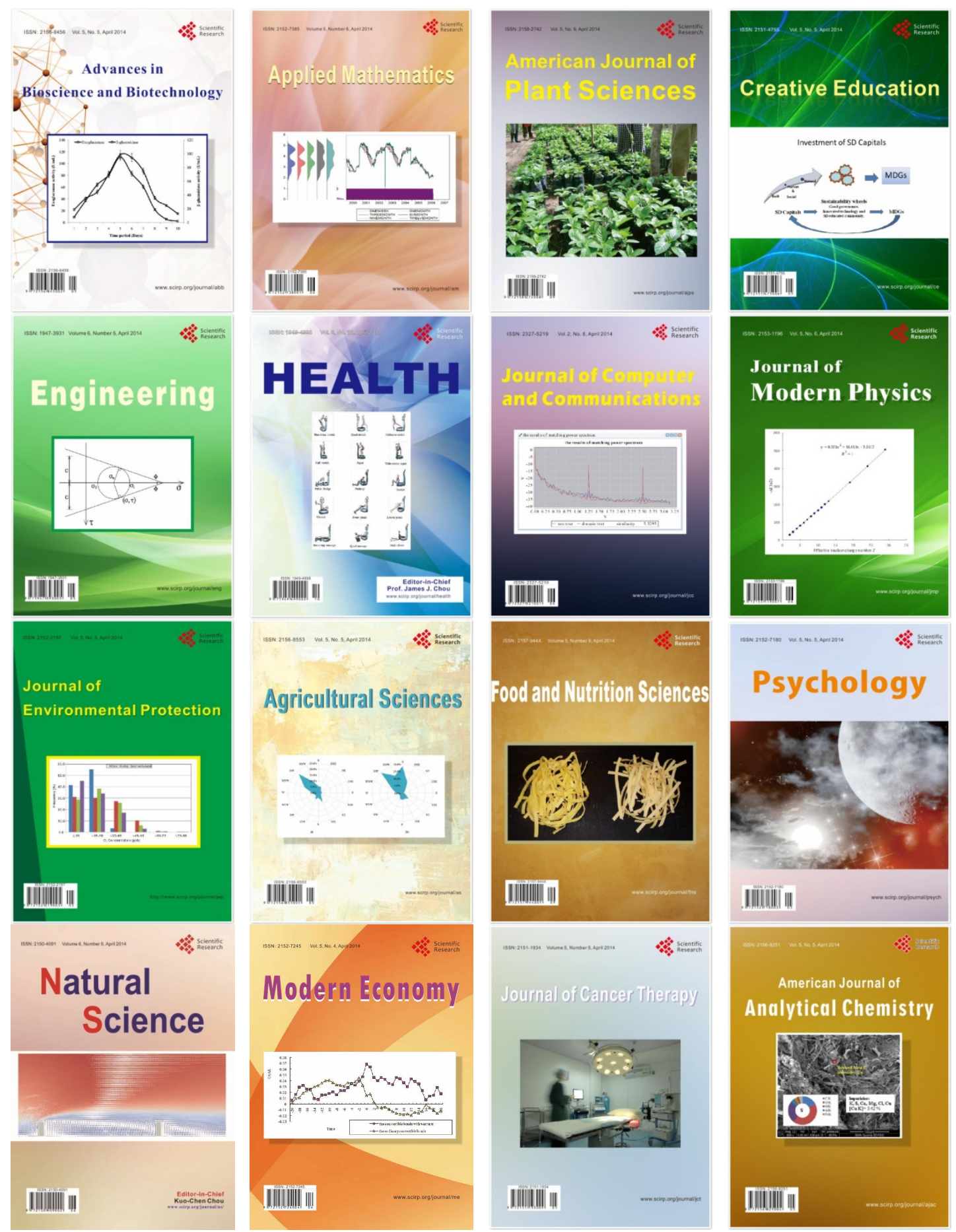